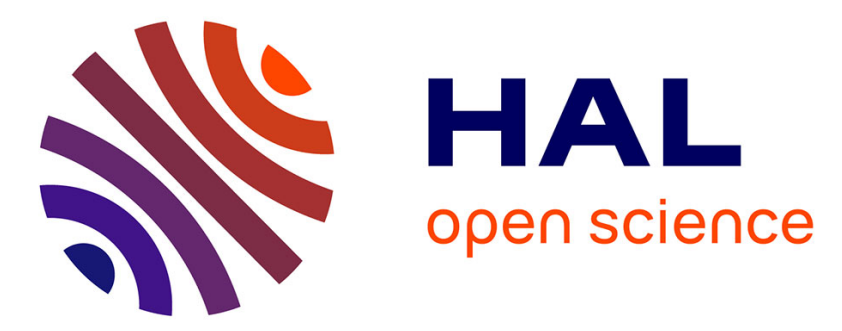

\title{
Reflexive learning, socio-cognitive conflict and peer-assessment to improve the quality of feedbacks in online tests
}

Franck Silvestre, Philippe Vidal, Julien Broisin

\section{- To cite this version:}

Franck Silvestre, Philippe Vidal, Julien Broisin. Reflexive learning, socio-cognitive conflict and peerassessment to improve the quality of feedbacks in online tests. 10th European Conference on Technology Enhanced Learning (EC-TEL 2015), Sep 2015, Toledo, Spain. pp. 339-351. hal-01363369

\section{HAL Id: hal-01363369 \\ https://hal.science/hal-01363369}

Submitted on 9 Sep 2016

HAL is a multi-disciplinary open access archive for the deposit and dissemination of scientific research documents, whether they are published or not. The documents may come from teaching and research institutions in France or abroad, or from public or private research centers.
L'archive ouverte pluridisciplinaire HAL, est destinée au dépôt et à la diffusion de documents scientifiques de niveau recherche, publiés ou non, émanant des établissements d'enseignement et de recherche français ou étrangers, des laboratoires publics ou privés. 


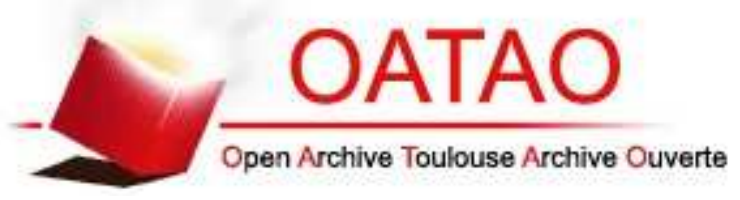

\section{Open Archive TOULOUSE Archive Ouverte (OATAO)}

OATAO is an open access repository that collects the work of Toulouse researchers and makes it freely available over the web where possible.

This is an author-deposited version published in : http://oatao.univ-toulouse.fr/ Eprints ID : 15337

The contribution was presented at EC-TEL 2015 :

http://www.ec-tel.eu/index.php?id=732

To cite this version : Silvestre, Franck and Vidal, Philippe and Broisin, Julien Reflexive learning, socio-cognitive conflict and peer-assessment to improve the quality of feedbacks in online tests. (2015) In: 10th European Conference on Technology Enhanced Learning (EC-TEL 2015), 15 September 2015 - 18 September 2015 (Toledo, Spain).

Any correspondence concerning this service should be sent to the repository administrator: staff-oatao@listes-diff.inp-toulouse.fr 


\title{
Reflexive learning, socio-cognitive conflict and peer-assessment to improve the quality of feedbacks in online tests
}

\author{
Franck Silvestre, Philippe Vidal, and Julien Broisin \\ Université Toulouse III Paul Sabatier, Institut de Recherche en Informatique de \\ Toulouse, 118 route de Narbonne, 31062 Toulouse Cedex 04
}

\begin{abstract}
Our previous works have introduced the Tsaap-notes platform dedicated to the semi automatic generation of multiple choice questionnaire providing feedbacks: it reuses interactive questions asked by teachers during lectures, as well as the notes taken by students after the presentation of the results as feedbacks integrated into the quizzes. In this paper, we introduce a new feature which aims at increasing the number of contributions of students in order to significantly improve the quality of the feedbacks used in the resulting quizzes. This feature splits the submission of an answer into several distinct phases to harvest explanations given by students, and then applies an algorithm to filter the best contributions to be integrated as feedbacks in the tests. Our approach has been validated by a first experimentation involving master students enrolled in a computer science course.
\end{abstract}

Keywords: Interactive questions, quality of feedback, reflexive learning, peer-assessment, socio-cognitive conflict

\section{Introduction}

Different studies $[12,9]$ show that computer-based assessments facilitate the provision of frequent formative assessments to large groups of students. Also, the quality of the feedback provided to students in the context of their works or of their assessments results is a key factor for better learning $[2,7,8]$. David Nicol \& DMD [10] recommend the use of online tests so the feedback is accessible to students anytime, from anywhere and as often as they wish. However, the feedback provided to students by traditional online learning management systems or other IMSQTI compliant platforms [11] is, by default, minimalist: for each question, it includes the student's score and the correct answer; additional and relevant feedback has to be produced by teachers manually, and this time consuming process is therefore not done very often.

We have described in [16] the approach "Note as Feedback" (NaF), implemented in our Tsaap-Notes platform [15]. Tsaap-Notes allows teachers to ask interactive questions during lecture, and students to answer questions and to take notes on each of these questions in following the presentation of the results given by all the participants. As Tsaap-Notes questions are written using 
the Moodle gift format, the approach "NaF" allows the teacher to generate in an automatic way a Moodle compatible quiz composed of (1) the interactive questions asked by the teacher during the lecture, and (2) the notes taken by the students on those questions; these notes represent the feedback exposed to students when they perform the quiz within Moodle.

Despite the promising results of the first experimentation, two limits have been clearly identified in the current Tsaap-Notes implementation. 1- Every single note taken by students on a given question is automatically included into the feedback of the quiz; the notes are not evaluated nor filtered, there is no "quality check" of the feedback. 2- Only few students participate in the writing of explanations that are required to build relevant feedbacks. Thus, in this paper, we present a new feature to manage interactive questions called "question with submission of answer in n-phases" (NP-Q) dealing directly with the two limits mentioned above: interactions implemented in NP-Q maximize on one hand the students' participation in the writing of an explanation, and on the other hand enable students to assess the different analysis they made. In addition, the "best" contributions only are integrated as source of feedback into the Moodle quiz. The article is organized as follows : Section 2 presents the scientific sources which have inspired the making of NP-Q ; Section 3 shows the implementation of NP-Q in Tsaap-Notes; Section 4 relates the results of the first experimentation made with a group of 51 Master students from Paul Sabatier University (Toulouse III). We conclude in section 5 and present some future works.

\section{Why the NP-Q Feature?}

A limit highlighted by the first experimentation conducted with the NaF feature of Tsaap-Notes is the low engagement of students in the note-taking process. Indeed in [16], results show that only $25 \%$ of students take notes, even though $75 \%$ of students participate in interactive questions [15]. This limit affects the creation of revision tests because there are not enough feedbacks, and it affects the lecture itself as well. When three quarters of students answer multiple choice questions, why only one quarter participates in the writing of an explanation?

Scouller reminds that assessments influence the learning process considerably [13]: the way a student is assessed determines how, what, and how much he will learn. Most students put their efforts in acquiring knowledge and cognitive abilities on what they know they will be assessed on. In [1], Biggs and Tang explain that active educational methods, where students deal with activities aligned with the learning target and with the assessment tasks, stimulate a better and thorough learning approach for them. Both authors put forward the fact that "formative assessments" provide the student with the feedback allowing him to know where he stands. The positive impact of interactive vote systems on the involvement of students shown through different studies $[4,6,14,18]$ is due mainly to the formative assessment function: during a lecture, students are able to notice in real time their level of knowledge or cognitive ability, whether individually or compared to a group. 


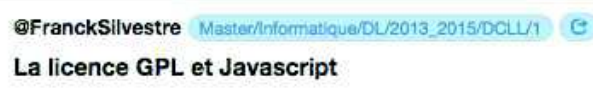

Soit $L$ une librairie javascript distribuée sous licence GPL. Soit $E$ une entreprise qui modifie la librairie $L$ pour en faire une version L2. L'entreprise E propose à des utilisateurs son application serveur qui utilise la version $\mathrm{L} 2$ de la librairie. Est ce que les utilisateurs peuvent exiger de récupérer le code source de la version $L 2$ du logiciel?

Oui

Give an explanation to your choice

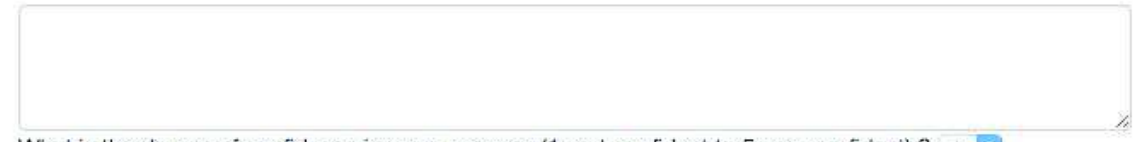

What is the degree of confidence in your response ( 1 : not confident to 5 :very confident) ? 1

Fig. 1. Submission of an answer with the NP-Q feature: first phase

Starting from these findings and to increase the participation rate in the writing of an explanation about a question during a lecture, our hypothesis stands on the fact that students should be provided with immediate feedback about their notes. Thus, the different phases of the NP-Q feature have been designed to promote reflexive learning, and expose to each student a feedback going from the comparison of alternative answers generating a socio-cognitive conflict, to the presentation of the assessment result of his explanation. In addition, as the quick assessment of a large number of explanations cannot be performed by a single teacher during a lecture, we have adopted a peer-assessment process whose properties have been demonstrated in different studies $[3,5,17]$.

Finally, to tackle the other limit shown by the experimentation of the $\mathrm{NaF}$ feature (i.e. the integration of all contributions from the students in the feedbacks of the revision tests generated by Tsaap-Notes), the assessments of the notes by students are analysed by an algorithm to select the best contributions only.

\section{Conception and Implementation of the NP-Q Feature}

In this section, we describe how the NP-Q feature has been implemented into the Tsaap-Notes environment in order to integrate the writing of explanations within an activity allowing (1) students to get an immediate feedback about their contributions, and (2) a quick peer-assessment on the whole set of contributions. 
@FranckSilvestre Master/informatique/L/2013,2015/OCL/1/ c

13 janvier 2015 15:32

Here is an alternative response to yours.

Please examine this response and then feel free to change your response, explanation or confidence degree if necessary.

Oui

Le javascript étant exécuté côté client, l'utilisateur a une copie, la contamination du GPL force donc

la possibilité dªccès au code à l'utilisateur.

La licence GPL et Javascript

Alternative answer

Soit $L$ une librairie javascript distribuée sous licence GPL. Soit $E$ une entreprise qui modifie la librairie $L$ pour en faire une version L2. L'entreprise E propose à des utilisateurs son application serveur qui utilise la version $L 2$ de la librairie. Est ce que les utilisateurs peuvent exiger de récupérer le code source de la version $L 2$ du logiciel?

Oui

CNon

Give an explanation to your choice

En tant qu'utilisateurs de l'application serveur, on se retrouve dans le même cas que précédemment, on n'a pas de copie du logiel. On ne peut donc toujours pas exiger récupérer le code.

What is the degree of confidence in your response ( 1 : not confident to 5 :very confident) ? 3

Submit Second submission form: a chance to modify the first answer

Fig. 2. Submission of an answer with the NP-Q feature: second phase

\subsection{Main Principles}

The activity we introduced consists in the separation of the submission of an answer of a multiple choice question in several phases. The first phase exposes a form illustrated in Fig. 1 and allows students to (1) answer a multiple choice question, (2) enter the explanation of their choice, and (3) indicate the confidence level of their answer. Thus, at this stage, the student turns into a reflective learning situation as he has to reflect on his own knowledge and abilities as soon as he indicates the level of confidence in his answer. This indicator represents also one of the key elements of the algorithm underlying the second phase. Although the example posed in Fig. 1 is a true/false question, the system supports general multiple choice questions.

The second phase of the submission process consists of providing the student with the form illustrated in Fig. 1, already filled in with his answer and explanation, together with an alternative answer submitted by another student participating in the same interactive session; the resulting interface is exposed on Fig. 2. This phase gives the student a first feedback through the suggestion of another answer and analysis, thus turning him into a situation of socio-cognitive 
(6FranckSilvestre Mastar/lintormatique/OL/2013 2015/DCLU/1 (e)

13 janvier 2015 15:32 Results La licence GPL et Javascript - (response count : 4)

Soit $L$ une librairie javascript distribuée sous licence GPL. Soit $E$ une entreprise qui modifie la librairie $L$ pour en faire une version L2. L'entreprise $E$ propose à des utilisateurs son application serveur qui utilise la version $L 2$ de la librairie. Est ce que les utilisateurs peuvent exiger de récupérer le code source de la version $L 2$ du logiciel ?

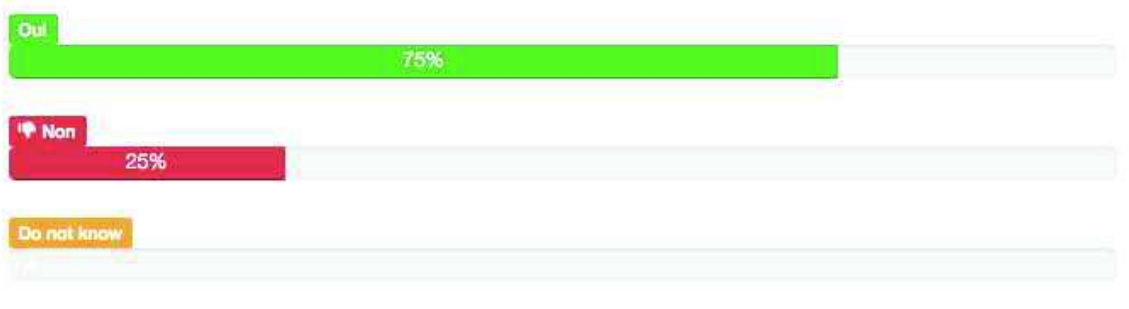

Your score : $0.0 \%$

A last work waits for you: please give a grade to the explanations given for the good answer (1: "not usefull" to 5: "very usefull").

Le javascript étant exécuté côté client, I'utilisateur a une copie, la contamination du GPL force donc la possibilité d'accès au code à l'utilisateur.

4 c

L2 est en licence GPL, et s'execute sur le poste de l'utilisateur. II est donc titulaire de la copie, et peut donc demander le code source.

5 ic

Sous licence GPL, Cecill (equivalent pour le droit français), toute modification/extension doit être distribuée sous licence compatible;

2 \&

Submilt:

Fig. 3. Submission of an answer with the NP-Q feature: third phase

conflict as he has to compare his own answer with the one of his peers. The student can then confirm his choice and explanation, or he can modify his answer. Let us note that, in order to avoid relational influences, no information about the identity of the other peer is known by the student.

During the third and last phase, each student is provided with (1) the results of all students who answered the question, and (2) his own score on the question. In addition, the peer-assessment of the students' contributions takes place during this phase: through the interface illustrated in Fig. 3, each student is asked 
to assess three distinct explanations of the right answer using a Likert scale graduated from 1 to 5 .

Once this phase is completed, Tsaap-Notes calculates the average rating for each assessed explanation, and presents to students the results of the assessment process in a descending order. Finally, the feedbacks integrated into the Moodle quizzes comprise the explanations characterised by an average value higher than 2.5 only; the resulting Moodle interface is shown in Fig. 4.

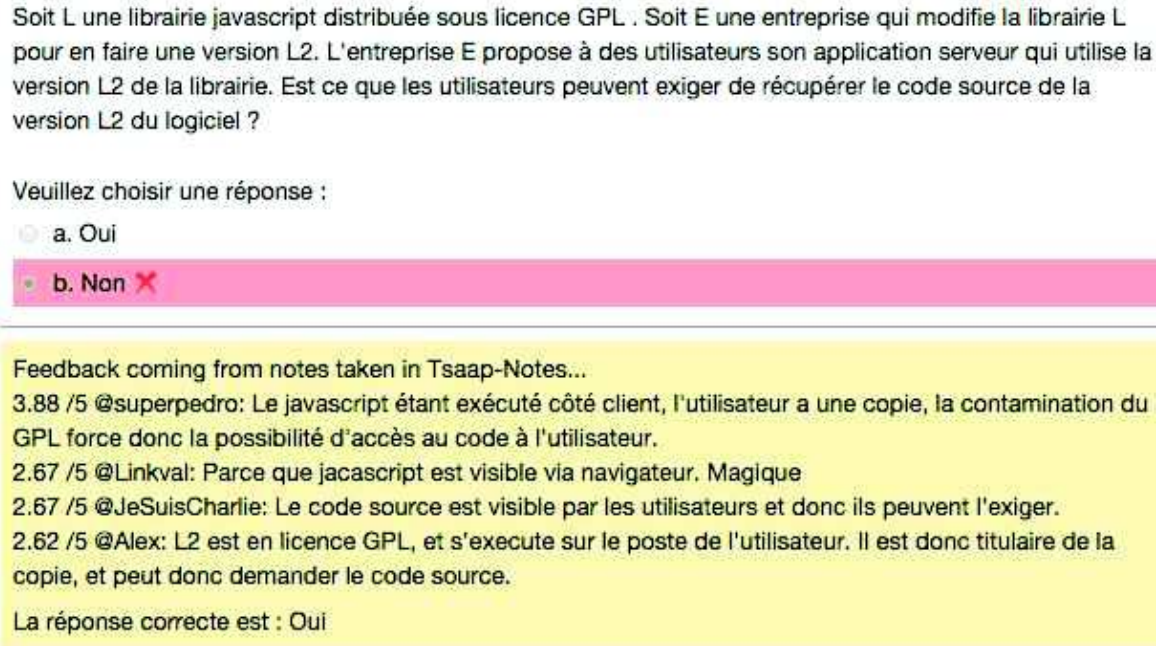

Fig. 4. A Moodle question integrating the feedback coming from Tsaap-Notes

\subsection{Focus on the Algorithm Provoking a Socio-Cognitive Conflict}

To generate a socio-cognitive conflict, the second phase of the NP-Q feature requires an algorithm capable of putting together two opposite and relevant answers given by students at the end of the first phase. Therefore, the main point of our algorithm consists in connecting an answer ai to an answer $a j$, where (i) both answers represent different choices, and (ii) the explanation associated with $a i$ is of reasonable length. If several answers can be connected to $a j$, then the algorithm selects those characterised by the higher level of confidence, and encourages diversity by exposing different associations to students when possible. In order to present our algorithm, we propose a formal representation of the problem along with the most relevant parts of the solution.

In the remaining of the document, $q$ represents a multiple choice question.

Definition 1. An answer a to a multiple choice question $q$ is a triplet

$$
a=(s ; d ; e)
$$


where

- $s$ is the calculated score of the student;

$-d$ is the level of confidence given by the student on his answer;

- $e$ is the number of characters in the student's explanation.

In the remaining of the document, $q$ represents a multiple choice question.

Property 1. Given $A$ the set of all answers got from $q$. The relation $\geq$ on $A$ defined by

$$
\forall\left(a_{i}=\left(s_{i} ; d_{i} ; e_{i}\right), a_{j}=\left(s_{j} ; d_{j} ; e_{j}\right)\right) \in A^{2}, a_{i} \geq a_{j} \Leftrightarrow d_{i} \geq d_{j}
$$

is an order relation on $A$.

Definition 2. The set $A_{c}$ of all correct answers to $q$ is defined as

$$
A_{c}=\left\{a_{i}=\left(s_{i} ; d_{i} ; e_{i}\right) \in A \mid s_{i}=\text { MaxScore }\right\}
$$

where MaxScore is the maximum score a student can obtain for a question $q$.

Definition 3. The set $\overline{A_{c}}$ of all incorrect answers to $q$ is the complementary of $A_{c}$ in $A$.

Definition 4. All the answers to $q$ able to generate a socio-cognitive conflict are included in the set $C$ defined as follows

$$
C=\left\{a_{i}=\left(s_{i} ; d_{i} ; e_{i}\right) \in A \mid e_{i}>\text { MinSizeExp }\right\}
$$

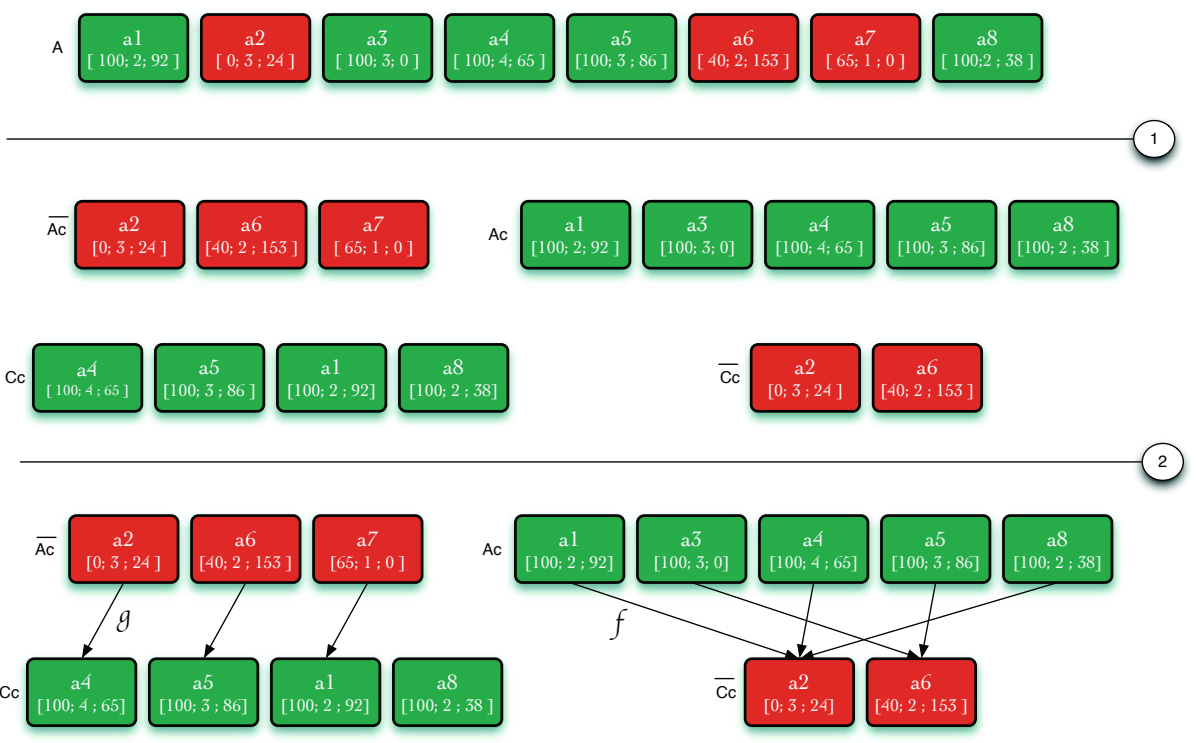

Fig. 5. The algorithm to generate a socio-cognitive conflict 
where MinSizeExp is the minimum size of an explanation so that the associated answer can be selected to generate a socio-cognitive conflict.

Definition 5. The set $C_{c}$ of all correct answers to $q$ able to generate a sociocognitive conflict is defined as follows

$$
C_{c}=C \cap A_{c}
$$

Definition 6. The set $\overline{C_{c}}$ of all incorrect answers to $q$ able to generate a sociocognitive conflict is the complementary of $C_{c}$ in $C$.

Definition 7. Given $A_{c}=\left\{a_{1}, a_{2}, a_{3}, \ldots, a_{n}\right\}$ where $\forall(i, j) \in\{1, . ., n\} \quad i<j \Rightarrow$ $a_{i} \geq a_{j}$ the ordered set of all correct answers to $q$.

Given $\overline{C_{c}}=\left\{c_{1}, c_{2}, c_{3}, \ldots, c_{p}\right\}$ where $\forall(i, j) \in\{1, . ., p\} \quad i<j \Rightarrow c_{i} \geq c_{j}$ the ordered set of all the incorrect answers to $q$ able to generate a socio-cognitive conflict.

The function $f: A_{c} \rightarrow \overline{C_{c}}$ is the function which associates to each element $a_{i} \in A_{c}$ the element

$$
f\left(a_{i}\right)=c_{i} \bmod p
$$

where $i \bmod p$ is the remainder of the Euclidian division of $i$ by $p$.

Definition 8. Given $\overline{A_{c}}=\left\{a_{1}, a_{2}, a_{3}, \ldots, a_{n}\right\}$ where $\forall(i, j) \in\{1, . ., n\} \quad i<j \Rightarrow$ $a_{i} \geq a_{j}$ the ordered set of all incorrect answers to $q$.

Given $C_{c}=\left\{c_{1}, c_{2}, c_{3}, \ldots, c_{p}\right\}$ where $\forall(i, j) \in\{1, . ., p\} \quad i<j \Rightarrow c_{i} \geq c_{j}$ the ordered set of all the correct answers to $q$ able to generate a socio-cognitive conflict.

The function $g: \overline{A_{c}} \rightarrow C_{c}$ is the function which associates to each element $a_{i} \in \overline{A_{c}}$ the element

$$
g\left(a_{i}\right)=c_{i} \bmod p
$$

where $i \bmod p$ is the remainder of the Euclidian division of $i$ by $p$.

Starting from these definitions, Fig. 5 shows the different steps implemented within our algorithm. The first step takes the set $A$ as input, and creates the four sets $A_{c}, \overline{A_{c}}, C_{c}$ and $\overline{C_{c}}$; these sets are represented as ordered lists according to the relation introduced in Prop. 1. Since the maximum score that can be attributed to a question is always 100 in the current implementation of TsaapNotes, MaxScore has been set to this value as well; MinSizeExp (see Def. 4) has been arbitrary set to 10 . The second stage of the algorithm gathers into a dictionary the results of the application of $f$ (respectively $g$ ) on all the elements of $A_{c}$ (respectively $\overline{A_{c}}$ ). This algorithm has been experimented with several groups of students; the results are detailed in the next section.

\section{Results of the First Experimentation}

The NP-Q feature offered by Tsaap-Notes has been experimented with two groups of students in two courses integrated in the first year of a Computer 
Science Master program. The experimentation took place during 3 sessions of 2 hours during which 5 NP-Q questions were asked to students. Table 1 shows that almost $88 \%$ of students submitted an answer to each question; this high participation rate conforms to other studies related to audience response systems.

Table 1. Participation rates

\begin{tabular}{cccc||c}
\hline Course label & $\begin{array}{c}\text { Question } \\
\text { code }\end{array}$ & Number of presents & $\begin{array}{c}\text { Number of } \\
\text { submitted } \\
\text { answers }\end{array}$ & $\begin{array}{c}\text { Participation } \\
\text { rate }\end{array}$ \\
\hline DCLL & DCLL-1 & 51 & 37 & $72.5 \%$ \\
DCLL & DCLL-2 & 51 & 41 & $80.4 \%$ \\
MA & MA-1 & 34 & 34 & $100 \%$ \\
MA & MA-2 & 34 & 34 & $100 \%$ \\
MA & MA-3 & 34 & 32 & $94.1 \%$ \\
\hline Average & NR & 40.8 & 35.6 & $87.8 \%$ \\
\hline
\end{tabular}

A more interesting indicator is the participation of students in the submission of an explanation: Figure 6 shows that $68.29 \%$ of students that answered a question also submitted an explanation to justify their answers. Even if this participation rate is below the observed rate on submitted answers (i.e. $87.8 \%$ ), it represents a very large increase compared to the values resulting from a previous experimentation conducted in 2014 [15]. In this experimentation that involved a group of 35 students, questions were exposed using the "traditional" way (i.e. without the NP-Q feature) and students were invited to submit explanations

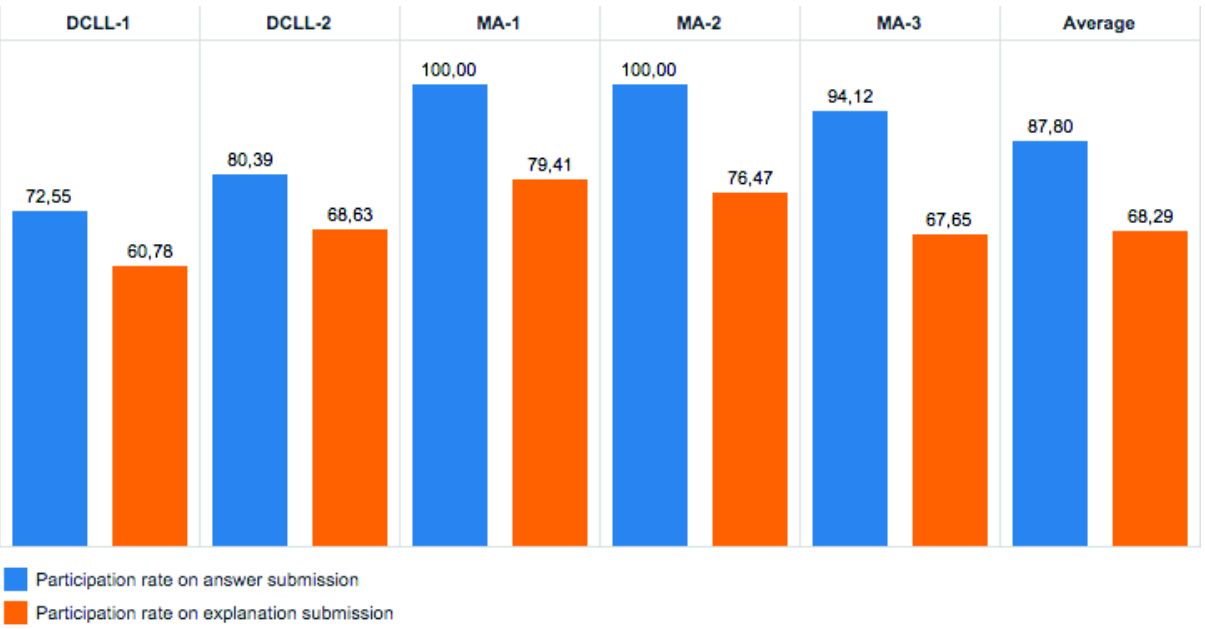

Fig. 6. Participation rates on answer submission/explanation submission 


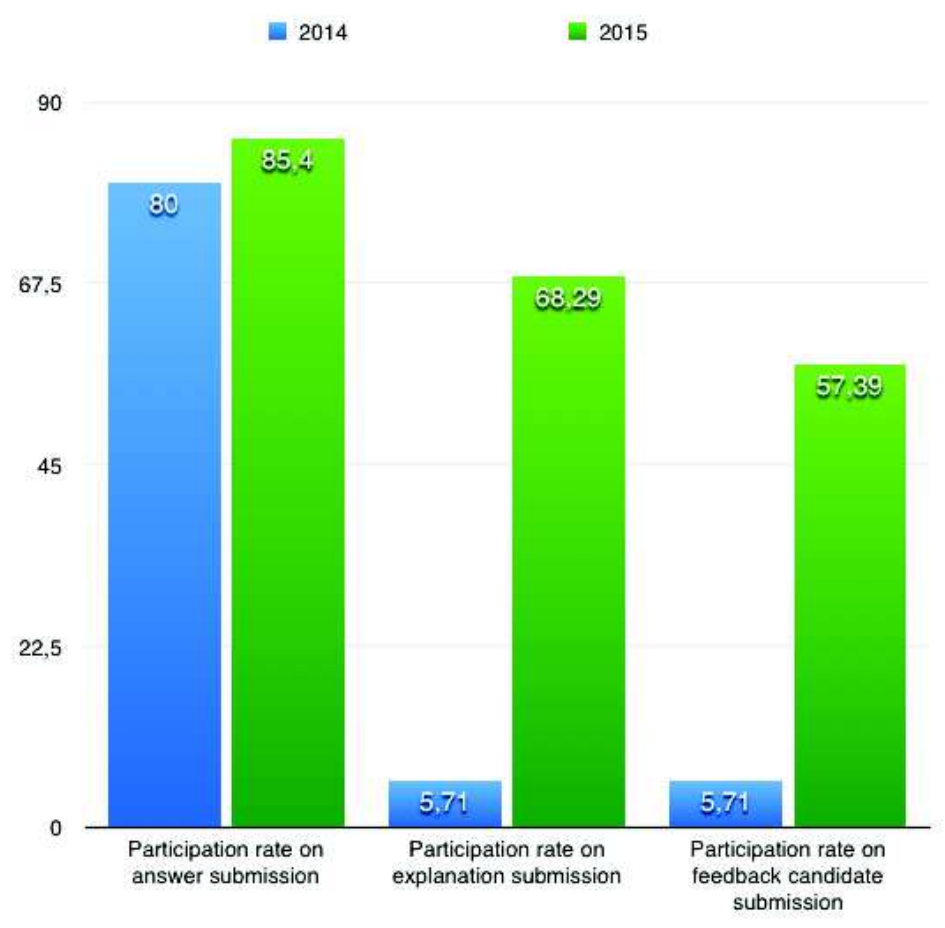

Fig. 7. Compared study on the participation rate for the writing of explanation

after the presentation of the results. Figure 7 shows that the NP-Q feature has strongly increased the participation rate in writing explanations: in average, only $5.7 \%$ of students were engaged in this task in 2014, compared with $68.29 \%$ of them in 2015. In addition, the number of contributions likely to be used as feedback in the Moodle quiz is much higher in 2015: $57.39 \%$ of the students' input are selected, against $5.7 \%$ in 2014 only.

Moreover, Fig. 8 shows that several students have altered their answer between the first and second phases: the socio-cognitive conflict made those students think about both their own and peers' knowledge. Since this conflictive approach brought $30 \%$ of students having submitted a wrong answer to identify the right answer, we consider this result as a strong encouragement to further explore the ability to provoke socio-cognitive conflict through Tsaap-Notes.

Finally, Fig. 9 gives the results of the last NP-Q phase where students are asked (but not required) to evaluate three explanations, and shows that $75.6 \%$ of them participated in this peer-assessment process. Thus, the average number of learners evaluating an explanation is 4.17 , for an average of 40.8 attending students and 22.8 explanations to evaluate; we estimate this average as significant enough to obtain a representative grade for an explanation. Furthermore, the average of the standard deviation related to the rates given by students on an 
explanation is 0.98 . This standard deviation is quite significant as it shows that the rates vary by $20 \%$ from one student to another, which is reasonable for our use (i.e. the selection of the highest rated explanations to build the feedback integrated into the Moodle quiz).

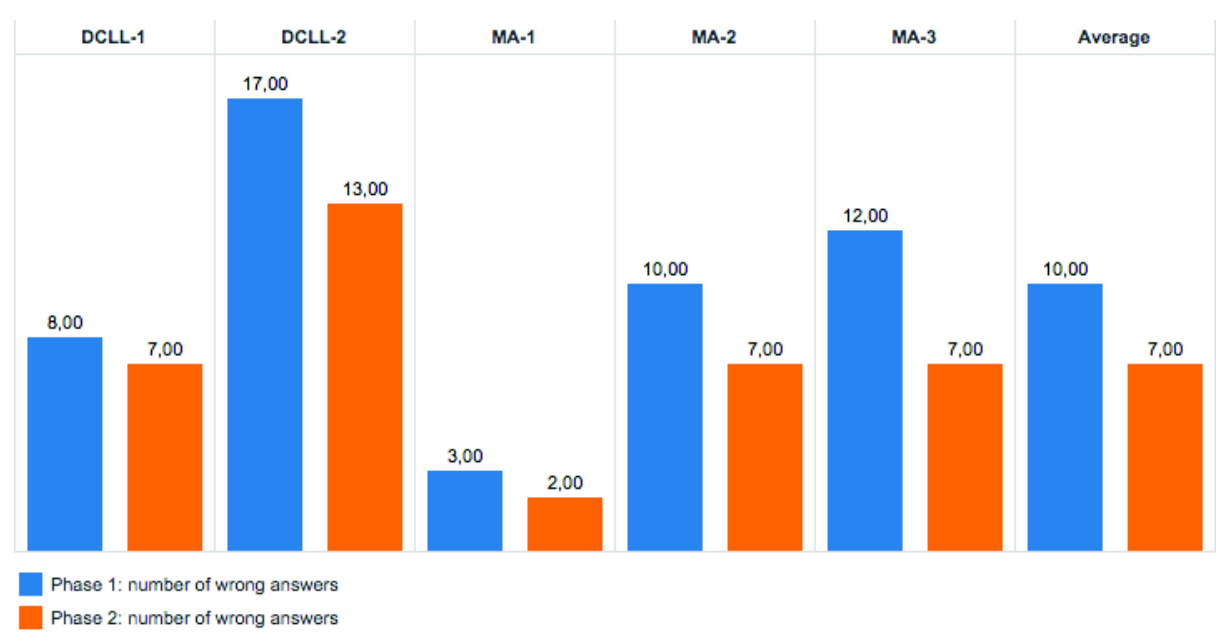

Fig. 8. Number of wrong answers in phase 1 and phase 2

\section{Conclusions and Perspectives}

The Tsaap-Notes platform enables the semi-automatic generation of a multiple choice test questions providing feedbacks on the basis of (1) the interactive questions asked by teachers during face-to-face lectures, and (2) the notes taken by students to create the feedbacks presented to students within the quizzes. In this paper, we introduced the NP-Q feature in order to considerably increase the number of contributions made by students, and thus to significantly improve the quality of feedbacks integrated in the generated quizzes. Our proposal splits the submission of an answer in several phases and places students in three distinct situations: reflexive learning, socio-cognitive conflict, and peer assessment. The best rated explanations of correct answers are then used as feedbacks to improve the quality of the formative assessments. The results of the first experimentation conducted with two groups of students enrolled in a computer science Master course are very promising, as they show a very strong increase of the students' participation in the writing of explanations; the selection of the most appropriate contributions can thus apply to a significant amount of data and make the feedbacks integrated into the quizzes more relevant.

Today, the algorithm triggering the socio-cognitive conflict takes into account a few information concerning the learners: only the score, the size of the expla- 


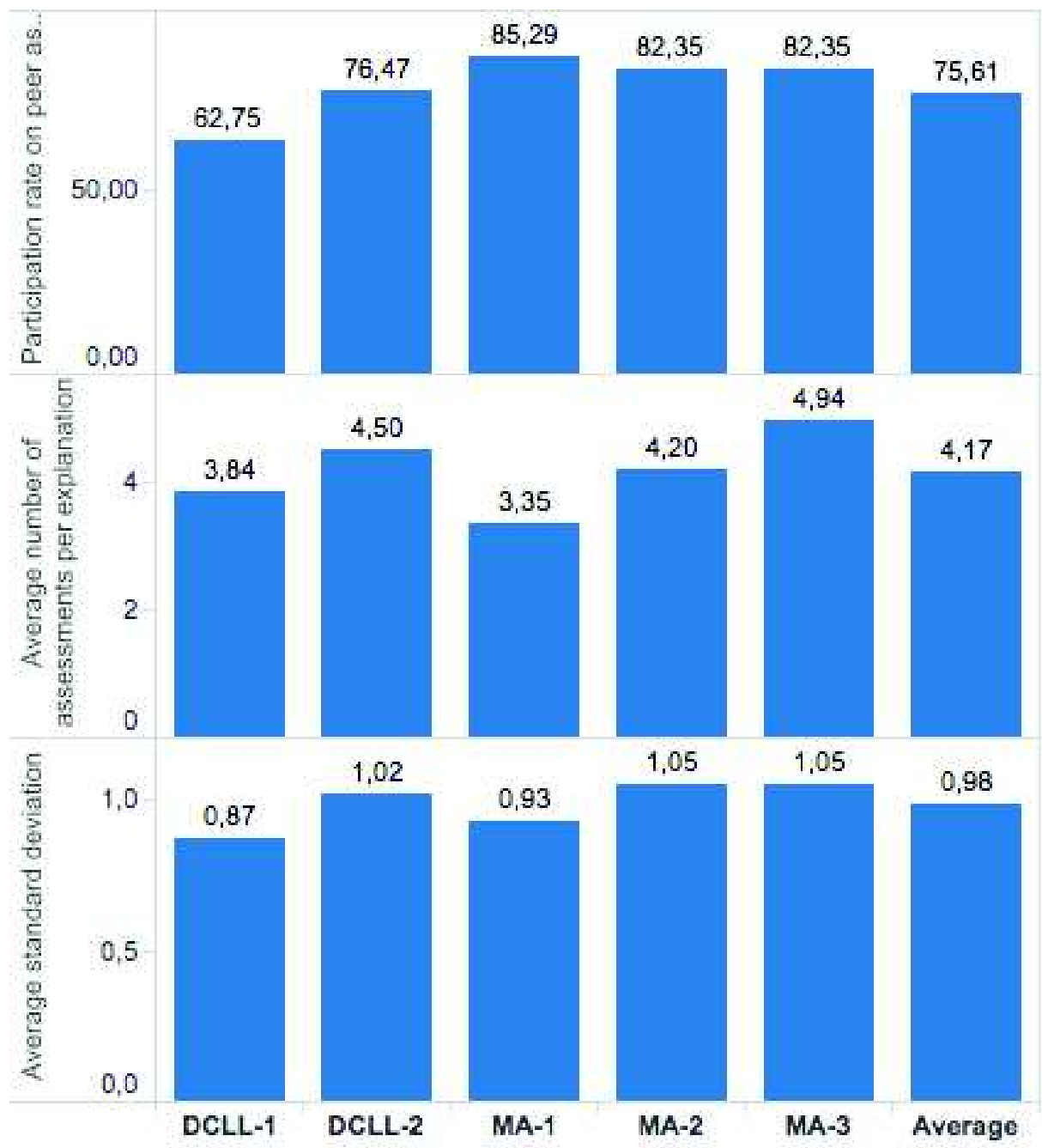

Fig. 9. Participation rate on peer assessment

nation and the level of confidence on a given question are used to influence an alternative answer. The results obtained at different questions or the ability to convince (i.e to make another student change his mind during a socio-cognitive conflict) represent other data that could be used to improve this algorithm.

The NP-Q feature is currently used during face-to-face lectures, but it would be interesting to adapt and try it in the context of a Massive Online Open Course (MOOC). Indeed, MOOC often integrate platforms like forums allowing learners to help each other. However, this kind of platform doesn't guarantee the participation of all learners, and therefore doesn't ensure that they get support from their peers. On the other hand, the generation of a socio-cognitive conflict 
the way it is proposed in this paper makes use of the productions of all the learners, for all the learners.

\section{References}

1. Biggs, J., Tang, C.: Teaching for quality learning at university: What the student does. McGraw-Hill Education (UK) (2011)

2. Black, P., Wiliam, D.: Assessment and classroom learning. Assessment in education 5(1), 7-74 (1998)

3. Boud, D., Cohen, R., Sampson, J.: Peer learning in higher education: Learning from and with each other. Routledge (2014)

4. Caldwell, J.E.: Clickers in the large classroom: Current research and best-practice tips. CBE-Life Sciences Education 6(1), 9-20 (2007)

5. Dochy, F., Segers, M., Sluijsmans, D.: The use of self-, peer and co-assessment in higher education: A review. Studies in Higher education 24(3), 331-350 (1999)

6. Gauci, S.A., Dantas, A.M., Williams, D.A., Kemm, R.E.: Promoting studentcentered active learning in lectures with a personal response system. Advances in Physiology Education 33(1), 60-71 (2009)

7. Hattie, J., Jaeger, R.: Assessment and classroom learning: A deductive approach. Assessment in Education 5(1), 111-122 (1998)

8. Higgins, R.: Be more critical: rethinking assessment feedback.. DYE. V, PC4000. (2000)

9. Miller, T.: Formative computer-based assessment in higher education: The effectiveness of feedback in supporting student learning. Assessment \& Evaluation in Higher Education 34(2), 181-192 (2009)

10. Nicol, D., Milligan, C.: Rethinking technology-supported assessment practices in relation to the seven principles of good feedback practice. Innovative assessment in higher education pp. 64-77 (2006)

11. QTI, I.: Question and test interoperability (2006)

12. Ricketts, C., Wilks, S.: Improving student performance through computer-based assessment: Insights from recent research. Assessment \& evaluation in higher education 27(5), 475-479 (2002)

13. Scouller, K.: The influence of assessment method on students' learning approaches: Multiple choice question examination versus assignment essay. Higher Education 35(4), 453-472 (1998)

14. Shaffer, D.M., Collura, M.J.: Evaluating the effectiveness of a personal response system in the classroom. Teaching of Psychology 36(4), 273-277 (2009)

15. Silvestre, F., Vidal, P., Broisin, J.: Tsaap-notes-an open micro-blogging tool for collaborative notetaking during face-to-face lectures. In: Advanced Learning Technologies (ICALT), 2014 IEEE 14th International Conference on. pp. 39-43. IEEE (2014)

16. Silvestre, F., Vidal, P., Broisin, J.: Semi automatic generation of online tests providing feedbacks based on collaborative note taking. In: Advanced Learning Technologies (ICALT), 2015 IEEE 15th International Conference on. IEEE (to appear)

17. Topping, K.: Peer assessment between students in colleges and universities. Review of educational Research 68(3), 249-276 (1998)

18. Uhari, M., Renko, M., Soini, H.: Experiences of using an interactive audience response system in lectures. BMC Medical Education 3(1), 12 (2003) 